already familiar with. The surgeon's "works" were limited and conditioned by his "faith." It was because Lister "dreamed dreams" that he worked away with carbolic putty. And so it will be to-day. We have all been familiar with the slow healing by granulation of these sorely infected wounds and with the resulting extensive scarring. The teaching of "modern antiseptics" demands not only the practice of new technique, it calls perhaps even more for the raising of a new standard of surgical work; for new faith, for the visualizing of new possibilities, and success will only come to those who have an enlarged and brighter hope.

\section{FURTHER OBSERVATIONS ON \\ THE RESULTS OF BLOOD TRANSFUSION IN WAR SURGERY,}

With Special Reference to the Results in Primary haemorrhage.

BY

I. BRUCE ROBERTSON, B.A., M.B.Toronto, IIAJOR C.A.M.C. With a Note by

C. GORDON WATSON, C.M.G., F.R.C.S., Colonel A.M.S., Constlting SURGeon B.E.F.

Is a previous paper ${ }^{1}$ the results of blood transfusion in a few cases of secondary haemorrhage were given, with a description of the Lindeman syringe-cannula method. ${ }^{2}$ Since that time opportunity has arisen of extending its application to cases of severe primary haemorrhage (accompanied by shock). The results of these cases are presented in this paper. In four cases of this series the citrate method was used; one case was done with the Unger two-way stopcock, the remainder by the Lindeman syringe-cannula method. The results have shown:

1. That certain cases heretofore considered as inoperable, and others as exceedingly bad. surgical risks, may often be revived to a degree which not only permits of radical operative measures, but ensures a good prospect of ultimate recovery.

2. That in other cases in which the post-operative condition is one of progressively increasing shock, due to the initial loss of blood and to the severity of the operative measures required, blood transfusion is a permanent resuscitative measure of extreme value.

It has been the unhappy lot of every surgeon in a casualty clearing station to have cases admitted-under his care which required immediate operative attention, but were in such a collapsed and exsanguine condition that pperation was out of the question. In certain of these cases a short operation (frequently amputation) is all the pperative treatment:immediately necessary, but the patient is unfit to withstand any operation owing to loss of blood and shock. Case 10 is typical of this class.

\section{The Time for Blood Transfusion.}

If the bleeding point can be controlled, as in the case of a shattered leg or thigh, the ideal time is as soon as the patient is seen. If operative interference is necessary before the bleeding can be controlled-for example, in intraibdominal haemorrhage-blood transfusion may be carried out before the patient leaves the operating table. Usually, however, one is tempted to employ the ordinary resuscita. ive measures before resorting to blood transfusion, but it is unwise to wait too long.

Clinical observation appears to show that some degenera- tive changes take place in the organism when the exsanguinated condition persists for more than a few hours. If the patient is allowed to reach this stage he does not receive the same amount of benefit from the transfusion as when giren earlier. For this reason it is advisable to give the blood as soon as possible after admission if circumstances permit.

Other great factors besides loss of blood in the pro. Auction of shock are loss of body heat and physical exhaustion. After blood transfusion these other factors may be combated by providing warmth and rest for a few - hours before operation. Acidosis incident to the shocked condition may be treated by the administration of sodium bicarbonate. It is obvious that in severely wounded and exsanguinated patients there is a greater liability to the development of severe infection during their subsequent progress than if the anaemia were decreased by the addition of fresh blood.

The benefit of blood trans'usion has its limitations, and it should not be used indiscriminately. It is, for example, of more limited value where gas gangrene has already developed, and should not be done unless the infected area can be either brought under control by excision or free drainage, or eliminated by ampitation.

\section{Amount of Blood to be Transfused.}

This depends largely upon the giving capacity of the donor and the receiving capacity of the patient. A small patient will require proportionately less blood than a large heavily-built patient to produce the same effect on pulse and blood pressure. In severe primary haemorrhage 700 to 1,000 c.cm. may be regarded as an average amount, and will usually tide the patient over his crisis. Smaller amounts have been given with some success, but the most immediate and lasting improvement has been obtained with the large amounts. Cardiac dilatation in these ex. sanguinated recipients has not been observed even with the larger amounts. In transfusing 1,000 or $1,200 \mathrm{c.cm}$. the intervals between the injections of the blood-filled syringes should be longer towards the later part than at the beginning of the procedure, and the minimum amount of saline should be introdinced into the recipient's vein between the injections of the blood-filled syringes.

The effects of loss of blood will show themselves at different times in the donor according to his size and robustness, the amount of blood, the rate at which it is removed, and the particular method employed. An im. pressionable donor will exhibit symptoms earlier than one of phlegmatic temperament. In none of the donors has anything more than temporary disturbance been observed. This coincides with the observations made by Colonel Fullerton, ${ }^{3}$ who had the opportunity of keeping donors under observation for some considerable time after they had given blood to patients.

The advisability of transfusing blood in the following cases was determined by the general condition of the patient, the pulse, and evidence of severe haemorrhage, the prospect of recovery after transfusion and operation, and in the later cases the blood pressure. A wounded man who has lost much blood and has a blood pressure below $90 \mathrm{~mm} . \mathrm{Hg}$ is not a good subject for operation; with a blood pressure below $70 \mathrm{~mm}$. Hg he is in a precarious condition. Loss of blood intensifies to a very great degree the amount of shock produced by traumatism, and in the majority of such cases the immediate issue depends upon control or elimination of the effects of haemorrhage.

\section{Immediate Results.}

In the cases of severe primary haemorrhage accompanied by shock, blood transfusion frequently produces an immediate and almost incredible improvement. The change from a pallid, sometimes semi-conscious patient with a rapid flickering pulse to a comparatively liealthy-looking, conscious and comfortable patient with a slower and fuller pulse is dramatic evidence of the value of the transfused blood. The blood-pressure readings before and after show the remarkable change produced by the new blood. In those cases in which readings were taken during the subsequent forty-eight hours it was shown that this rise in blood pressure was well maintained. This is in marked contrast to the transient effect on the blood pressure of normal saline injections. The chart illustrates the gradual fall in pulse rate and rise in blood pressure during the blood transfusion. The immediate result of the transfusion is that it places the patient more on a footing with a man similarly wounded who has not lost more than a moderate anount of blood.

Reports of Cases.

CASE 1.-G.S.IT. Femur and Femoral Vessels : Amputation : Death.

Rf. T. M. Admitted November 23rd, 1916, in extreme collapse. Compound fracture of left femur; femoral vessels severed. Intravenous saline was followed by temporary im. provement for some hours, but condition was still inoperable. Blood transfusion ( $800 \mathrm{c.cm}$. by Unger two-way stopcock) was followed by immediate improvenent. Amputation above
fracture. Death in thirtiv-six hours from gas gangrene. 
CASE 2.-G.S.W. Knee: Amputation: Recovery.

Pte. J. S. S. Admitted December 10th, 1916. Shattering fracture of leg involving knee-joint; profuse bleeding. He had received intravenous saline at the field ambulance. He was in a condition of collapse; pulse 134 and barely perceptible. Blood transfusion (500 c.cm. by citrate method) was followed by moderate but definite improvement. Two hours later amputation above knee. Next morning the pulse was 82, and the general condition immensely improved. Further progress uneventful. Evacuated to base in two weeks. A note from England four months later stated that reamputation had been done; stump healed rapidly; patient's healtb good.

CASE 3.-G.S.IF. both Knees and-Feet: Haemoglobinuria : Death.

Driver F. H. Admitted December 29th, 1916, in poor condition. Left foot blown away; severe compound fracture of right foot, and penetrating wounds of both knee-joints. Antishock measures were carried out, and when some improvement had taken place the wounds were dealt with. Post-operative condition bad. One litre of gelatin solution (Hogan) intravenously was followed by some improvement. On the following morning the condition was very poor; blood transfusion (750 c.cm. citrate method) was followed by marked reaction, but some improvement which was only temporary. He died in twenty hours. Haemoglobinuria present. There is no doubt that death was hastened by the occurrence of haemolysis.

CASE 4.-G.S.IF. Shoulder: Eracuated to Base: Death Tuo Months Later.

Sapper B. O. J. Admitted January 6th, 1917, under the care of Captain S. J. Streight, C.A.M.C.; had bled profusely from a ragged perforating wound of the left shoulder. Compound fracture of scapula and head of humerus. Anti-shock measures were instituted, and twelve hours later operation was done; the shattered head of humerus was removed and torn circumflex worse. Six hours after operation blood transfusion $(760 \mathrm{c.cm}$. by citrate method) was followed by immediate improvement. Before transfusion the blood pressure was: systolic 75, diastolic 40 ; next morning : systolic 100 , and diastolic 75 . Improvement progressive. Evacuated to base four days later. Two months later he died at a base hospital from empyema following pneumonia. The progress of the wound had been slow but good.

Case 5.-G.S.W. both Louer Limbs : Death from Shock.

Pte. R. F. Admitted February 3rd, 1917, in collapse; severe multiple wounds of both lower limbs (left leg almost multiple wounds of both lower limbs (left leg almost severed) and left forearm and hand. Anti-shock measures hare instituted, and ten hours later, when some improvement operation. Post-operative condition very poor. Blood transfusion $(660 \mathrm{c.cm}$. by citrate method), five hours later, was followed by slight improvement which was not maintained. Died seven hours later from shock.

Case 6.-G.S.W. Popliteal Artery: Amputation : Gas Gangrene: Death from Pulmonary Embolus.

Pte. T. D. Admitted in night of February 7th, 1917, in very poor condition. A shell fragment had severed the left popliteal poor condition. A shell fragment had severed the left popliteal unfit for transport from the field ambulance for several hours. Anti-shock measures were instituted, and some hours later blood transfusion (700 c.cm.) was done. Three hours later amputation was performed above the seat of injury. The patient withstood the operation well, but gas gangrene was present in the stump the next day; the infection was controlled by free incision. Five days after amputation he died very suddenly with signs of pulmonary embolus. Necropsy disclosed a long clot extending from the tied end of the femoral vein to its junction with the internal iliac vein.

CASE 7.-Penetrating Wound of Abdomen: Gas Infection : Death.

Pte. A. T. H. Admitted February 27th, 1917, with penetrating bullet wound of the abdomen. Sixteen hours after laparotomy the pulse became much weaker and more rapid. Blood transfusion $(1,000$ c.cm.) was followed by remarkable and immediate improvement, the pulse dropping from 140 to 108 after mediate improvement, the pulse dropping from 140 to 108 after bacillus infection in a large retroperitoneal haematoma.

CASE 8.-G.S.W. Forearm: Circular Amputation: Secondary Amputation: Evacuated to Base.

Pte. T. Admitted April 21st, 1917 (under the care of Captain William Beggs, C.A.M.C.), in severe collapse. Bleeding from a shattered forearm had been profuse. Anti-shock measures were taken and five hours later circular amputation was performed. The post-operative condition became progressively worse for five hours when blood transfusion $(1,160 \mathrm{c.cm}$.) was worse for five hours when blood transfusion (1,160 c.cm.) was
done and was followed by immediate improvement. Before transfusion: radial pulse 120 and barely perceptible, lips and face colourless; after transfusion : pulse 85 and of good tension; the face showed much improved colour. Four days later secondery amputation, flaps closed. Evacuated to base on the fourth day in exoellent condition.

Case 9.-Multiple G.S.W.: Eventually Evacuated to England in Satisfactory Condition.

Tse.-Cpl. F. was admitted under the care of Captain Beggs, C.A II.C., with severe multiple wounds of arms and lests.
General condition very poor. Anti-shock measures for some hours; the left leg was then amputated and other wounds dealt with. The following day the general condition was poor; blood transfusion ( 500 c.cm.) was followed by immediate improvement. Further progress steady though slow. Evacuated to base on fourth day. Note received from base to the effect that the patient had been evacuated to England in satisfactory condition after severe illness.

Case 10.-Multiple G.S.W.: Poplitcal Tessels Torn : Evacuated to Lieut $\mathrm{V}$ Base.

Lieut. V. Admitted May 17th, 1917; wounded seven hours previously. Left leg and knee shattered, popliteal vessels torn, penetrating wounds of left thigh, buttock, and face. Radial pulse 120 but almost imperceptible; face blanched. radial pulse was imparceptible $40 \mathrm{~mm}$. Hg. Death seemed imminent. Blood transfusion $(1,100 \mathrm{c} . \mathrm{cm}$.) was followed by immediate improvement. After transfusion the pulse was 130; blood pressure: systolic 120 , transfusion the pulse was 130; blood pressure: systolic 120 ,
diastolic 90. Half an hour later amputation was performed above the knee and the other wounds dealt with. Apart from transient sepsis on the face of the stump, due to the amputation having been made at the level of other wounds, progress was uneventful. Evacuated to base eight days later in very good condition.

CASE 11.-G.S.IF. Elbou and Forearm: Evacuated to Base.

Sapper W. C. Admitted May 18th, 1917, in severe collapse wounded seven hours previously. He had bled profusely from shattered left elbow and forearm. Blood transfusion $(1,200 \mathrm{c.cm}$.) performed immediately, was followed by marked improvement. Before transfusion: pulse 154; blood pressure systolic 62, diastolic 0 . After transfusion: pulse 130 ; blood pressure: systolic 110, diastolic 80 . Seven hours later amputation above elbow. Two hours after operation, pulse 114 ; blood pressure: systolic 120, diastolic 80 . Further progress uneventful. prent to base in six days in good condition.

CASE 12.-Lower Leg Bloun auray : Slou Recovery.

Pte. J. J. Admitted May 18th, 1917; the lower part of the left leg had been blown away six hours previously. He was collapsed and blanched. Blood transfusion (900c.cm.) was followed by immediate improvement. Before transfusion: pulse 146 ; blood pressure : systolic 74 , diastolic $20(?)$. After trans fusion: pulse 92 . Half an hour later amputation below the knee. Seven hours after operation: pulse 118; blood pressure systolic 128, diastolic 70. Further progress good. Evacuated to base in six days. Two weeks later a note from England stated : "Flaps faiily clean; slow progress."

CASE 13.-Comminuted Fracture Femur and Thigh : Amputation : Death.

Pte. W. Admitted May 29th, 1917, five hours after having sustained a severe comminuted fracture of the femur extending into the knee-joint. He was collapsed. Blood transfusion $(1,000$ c.cm. was followed by immediate improvement in the general condition and appearance. Before transfusion : pulse pressure 110. Amputation above knee. The palse 100; blood the operation well, but died three days later of acute capillary bronchitis.

CASE 14.-G.S.W. Leg: Amputation: Evacuated to Base.

Pte. W. C. N. Admitted June 1st, 1917, with shattered right leg; he wasblanched and had bled profusely. Blood transfusion $(1,060$ c.cm.) was followed by immediate improvement. Before transfusion: pulse 112; blood pressure : systolic 90, diastolic 32. After transfusion : pulse 76 ; blood pressure : systolic 134, diastolic 100 . Half an hour later amputation above knee. The following day the patient was in excellent condition and was evacuated to the base.

CASE 15.-G.S.W.: Amputation Thigh and Arm: Evacuated

Driver L. H. B. Admitted May 29th, 1917 (under the care of Captain S. J. Streight, C.A.M.C.), with severe compound fracture of right tibia and fibula into the knee-joint, shattered right elbow and forearm, and penetrating wounds of the right thigh. Anti-shock measures were instituted. Amputations above the right knee and elbow were performed, and the other wounds dealt with. Post-operative condition became prowounds dealt with. Post-operative condition became pro(900 c.cm.) was done. Before transfusion: pulse 136; blood pressure: systolic 86, diastolic 54 . After transfusion: pulse uneventful; evacuated to base on fourth day in good condition.

CASE 16.-Multiple G.S.W. : Amputation : Recovery.

Second Lieut. M. Admitted in severe shock and collapse; wounded seven hours previously. Left forearm shattered; penetrating wounds of right knee-joint, calf, and foot; right ankle disorganized by large perforating wound; large dirty perforating wound of left loin opening into extraperitoneal space. Condition quite inoperable. Anti-shock measures were of little avail. Immediate improvement followed blood transfusion $(1,100$ c.cm.). Before transfusion : pulse 132 ; blood pressure: systolic 90, diastolic 33. After transfusion: pulse 140; blood pressure: systolic 120, diastolic 74. Four hours later, under gas and oxygen, amputation of left arm (gas gangrene); 
following day amputation above the right knee was performed. Further prouress was uneventful, and he was sent to the base four days later. A note was received from the base stating that ten days later the flaps were sutured, and three weeks after being wounded he was evacuated to England, " the wounds healing nicely and condition much improved.

CASE 17.-Perforating Wound Stomach : Laparotomy : Haemoglobinuria: Death.

Lieut. H. Admitted in shocked condition ; penetrating wound of abdomen; excessive amount of blood vomited. Laparotomy disclosed perforated stomach and active bleeding from severed gastro-epiploic artery; abdominal cavity full of bright blood. After operation pulse almost gone; patient very blanched. Blood transfusion $(1,000 \mathrm{c.cm}$.) done. Before transfusion: pulse 130; blood pressure: systolic 66, diastolic 0. After transfusion: pulse 92 ; blood pressure : systolic 170, diastolic 72 . High systolic pressure due to injection of pituitrin given at the end of operation. During transfusion there was slight respiratory distress after $140 \mathrm{c}$.cm. of blood had been injected, but it was difficult to judge on account of the effects of the anaesthetic was difficult to judge on account of the effects of the anaesthetic. Two hours later the pulse became weaker, and the patient died
in a few hours. At necropsy some haemoglobinuria was evident. There is no doubt that a haemolytic reaction due to the transfused blood hastened the death of this patient.

CASE 18.-G.S.W. involving Tibial Arteries: Gas Gangrene : Transfusion Delayed.: Double Amputation: Death.

Lce.-Cpl. A., admitted June 7th, 1917; wounded the previous day. Perforating wounds of both legs, severing both posterior tibial arteries. Practically moribund condition; inoperable. Anti-shock measures were carried out in the resuscitation ward with little effect. Some hours later gas gangrene was evident in both legs, and the patient was unconscious and pulseless. At this time it was thought that blood transfusion followed by operation would give him his only chance. The response to blood transfusion (1,000 c.cm.) was extraordinary. Breathing, which at first was shallow and sighing, became quiet and regular the pulse grew perceptibly, and though rapid was of good character. Colour returned to his face, and hali-way through the procedure he became conscious. At the end of the transfusion he quite conscious and talked rationally. Half an hour later double amputation above the knees was done under gas and oxygen, but the patient died at the end of the operation. Had circumstances allowed of an earlier transfusion I feel sure that a successful result might have been expected.

CASE 19.-G.S.W. Leg: Immediate Amputation : Transfusion :

Capt. A. C. T. Admitted June 13th, 1917; wounded five hours previously. There had been profuse haemorrhage from shattered leg. Pulse only 108, but of low tension. Immediate operative condition progressively worse. Two hours later the patient was very collapsed and could be roused only with difficalty. Blood transfusion (1,100 c.cm.). Before transfusion: pulse 108; blood pressure : systolic 66, diastolic below 20 . After transfusion: pulse 84; blood pressure: systolic 120, diastolic 66 . Half-way through transfusion the patient was quite conscious; at the end of the procedure he asked for a cigarette and smoked it with enjoyment. Further progress was uneventful. He was sent to the base in five days. Note from base stated "Condition suitable for immediate transference to Eugland.

CASE 20-Lefi Thigh Blown Away: Amputation: Death. Gunner W. Admitted June 18th, 1917, six hours after being wounded. Left thigh almost completely blown away below the middle ; severe shock and collapse. Blood transfusion (700 c.cm.) was followed by immediate improvement. Before transfusion: pulse 130 ; blood pressure: systolic 80, diastolic 50 . After transfusion: pulse 92; blood pressure: systolic 124 After transfusion: pulse 92; blood pressure: systolic 124,
diastolic 78 . Following this amputation was done, but the patient stood the operation badly and died ten hours later from shock.

CASE 21.-G.S.W. Hip, Leg, and Arm: Amputation below Fnee : Evacuated to Base in Good Condition.

Capt. G. S. T. Admitted June 17th, 1917 (under the care of Captain S. J. Streight, C.A.M.C.), in collapsed condition. Right leg shattered; compound fracture of right great trochanter : penetrating wound of arm. Blood transfusion (1,200 c.cm.). Before transfusion: pulse 134; blood pressure : systolic 70, diastolic 40 . After transfusion: pulse 94 ; blood pressure: systolic 128, diastolic 80 . Four hours later amputation below knee and other wounds dealt with. Sent to base in four days. He was evacuated to England in a satisfactory condition.

Case 22.-Buried: Abdominal Injuries and Fractured Femur: Laparotomy : Evacuated to Base in Good Condition.

Pte. F. McL. Admitted July 4th, 1917. Had been buried by a shell seven hours previously; was in a condition of shock \&nd collapse from intra-abdominal injury and fracture of femur. Anti-shock measures for some hours produced slight improvement. Laparotomy : abdomen full of bright blood and urine; two-inch tear in bladder; lower part of spleen completely torn away; profuse spurting of blood from the remainder at the first touch. Splenectomy and bladder suture. Thomas splint to thigh. During operation pituitrin $(1 \mathrm{c.cm}$.) was given and saline $(30 \mathrm{oz}$.) introduced into vein. At the end of the operation the patient was very blanched and the pulse poor. Blood transfusion (1,C00 c.cm.). Before transfusion: pulse 180; blood pressure: systolic 80 , diastolic 40 . After transfusion: pulse 140; blood pressure: systolic 185, diastolic 80 . High systolio pressure evidently due to pituitrin, as seven hours later it had dropped to 136, diastolic being maintained at 80 . Further progress uneventful. Evacuated to base in two weeks. Four weeks after operation a note was received from the base stating that the patient was in excellent condition and recovery seemed assured.

CASE 23.-G.S.T both Legs. Amputation: Evacuated to Base in Good Condition.

Pte. G. G. H. Admitted July 11th, 1917, in severe collapse. Compound fracture of left leg and rup. ture of both tibial arteries; large wound of right leg with tear of posterior tibial artery. Had bled profusely. Anti-shockmeasures produced little im. provement. Blood
transfusion c.cm.) was followed by immediate im. provement. Before provement. Before transfusion: pulse
144:; blood pressure: systolic 62 , diastolic 40. After trans. fusion: pulse 96 ; blood pressure: systolic 126 , diastolic, 60 . Several hours later amputation of left leg below knee, and other wounds dealt with. Further progress un-

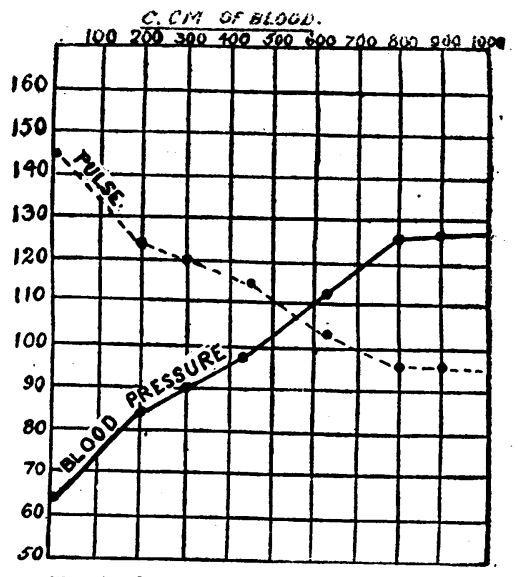

Chart of Case 23, showing fall in pulse rate and rise in blood pressure during of blood. base in four days in good condition. He was evacuated to England in good condition three weeks after being wounded.

CAse 24.-G.S.W. Popliteal Artery and Knee. Amputation :

Pte. F. Evacuated to Base in Good Condition.

Pte. F. S. Admitted in collapsed condition on July 12th, 1917 , seven hours after being wounded. Shell wounds of left buttock, leg, and foot; right popliteal artery severed and fracture of femur, involving right knee-joint. Anti-shock measures were carried out, with only temporary improvement. Four hours later blood transfusion $(1.000 \mathrm{c} . \mathrm{cm}$.). Before transfusion : pulse 156, blood pressure 80. After transfusion: pulse 120, plood pressure 136. Three hours later amputation above right knee, and other wounds dealt with, under gas-oxygen anaesthesia. Five hours after operation: pulse 128, blood pressure 120. Further progress uneventful. Evacuated to base on fifth day in good condition, with clean wounds and stump.

Case 25.-G.S.T. Chest, Femoral Vein, Knee-joint : Eracuated to Base in Good Condition.

Dr. C. J. B. Admitted in very grave condition under the care of Major G. E. Gask, D.S.O., R.A.M.C.(T.). Penetrating wound of chest; tear of left femoral vein ; penetrating wound of right knee-joint. After operation the patient was blanched and collapsed; the pulse was 180 and barely perceptible; blood pressure $60 \mathrm{~mm}$. Hg. Blood transfusion was started, but before $60 \mathrm{c.cm}$. had been injected death was imminent. The patient's lips were bloodless, pulse imperceptible, breathing slow and jerky; $80 \mathrm{c.cm}$. of very hot saline and $1 \mathrm{c.cm}$. pituitrin were now given intravenously and the transfusion continued were $400 \mathrm{c} . \mathrm{cm}$. of blood had been injected the breathing had improved greatly. At the end of the transfusion (1,200 c.cm.) the face was flushed, pulse strong, and the patient was attempting to clear his throat. After transfusion: pulse 108, blood pressure 144. Further progress uneventful. Evacuated to base seven days later. Two weeks later he had been evacuated to England in good condition.

CASE 26.-G.S.II. Chest: Haemothorax and Laceration of Lung: Death.

Gunner E. G., wounded early that morning, was admitted in very collapsed condition under the care of Major G. E. Gask D.S.O., R.A.M.C.(T.), on July 17th, 1917. Severe penetrating wound of chest; extensive damage to lung. Blood transfasion $(700 \mathrm{c.cm}$.$) . There was slight response lasting a very short$ time. Death occurred some five hours later. Necropsy showed gas bacillus infection in haemothorax, and severe laceration of lung.

CASE 27.-Penctrating Wound of Abdomen : Laparotomy : Death

Gunner C. H. W. Admitted July 25th, 1917, in collapsed and pulseless condition. Large penetrating wound of lover abdomen. Anti-shock measures were instisuted and pulse returned-96. Laparotomy eight hours instisuted and pulse ceived; resection of $18 \mathrm{in}$. of small gut; suture of bladder and
two tears in rectum. The abdomen was filled witl blood and clot; after operation the patient was pulseless. Blood trans fusion $(1,100 \mathrm{c.cm}$.) was done, but the patient was too far gons to benefit by it, and alied in less than three hous 

CASE 28. - Mtulliple G.S.W. both Lower Limbs: Amputation of
Thigh and Wrist : Evacuated to Base.

Lieut.-Col. - - R.A.M.C., aged 50, was admitted in collapsed condition seven hours after being wound 51 ; pulse almost imperceptible; face greyish-blue, condition inoperable. Severe compound fracture below right knee, penetrating wound right. knee-joint, right hand blown off, left brachial artery severed, large perforating wounds of left thigh. Blood transfusion large perforating wounds of immediate improvement. Four hours later operation was carried out under light chloroform anaesthesia, three teams being coneentrated on the case ; amputation above right knee, ligation of left brachial artery, excision of wounds of left thigh, amputation through right carpus. Further progress slow but good. Evacuated to base four days later; temperature $98^{\circ}$, pulse $88^{\circ}$. Two weeks later wounds reported to be improving.

CASE 29.-G.S.W. Chest: Recovery.

2nd Lieut. A. J. D. Admitted July 29th, 1917, under the care of Major G. E. Gask, D.S.O., R.A.M.C., in a collapsed condition; severe penetrating wound of chest, from which there had been a large amount of bleeding. Condition : inoperable. Blood transfusion ( $740 \mathrm{c.cm}$ ) carried out. After $100 \mathrm{c.cm}$. had been injected operation was begun. Thoracotomy, removal of shell fragments, irrigation of pleural cavity, closure of chest wall. Further progress good. Evacuated to base nine days later in good condition.

Case 30-G.S.W. both Legs: Double Amputation: Evacuated to Base in Good Condition.

Pte. H. G. Admitted on July 29th, 1917, six hours after being wounded, in very collapsed conllition. Right leg shattered and vessels torn ; extensive wound of left calf, with shell fragment embedded in muscles; pulse rapid and flickering, lips bluishwhite. Blood transfusion $(1,200 \mathrm{c.cm}$.). Two hours later emputation above right knee (for gas gangrene), left calf widely opened up. Next morning the patient was very much improved, but by evening gas gangrene of left leg was present, and amputation above the leit knee was done under gas-oxygen anaesthesia. The following day there "was persistent vomiting (acidosis), which was relieved by an intravenous injection of $20 \mathrm{oz}$. of 5 per cent. sodium bicarbonate solution. Further progress hneventful. Evacuated to base five days after admission in very good condition; both thigh stumps clean.

CASE 31.-Amputation of Forearm and Thigh: Gas Gangrene: Death

Gunner W. P. Admitted August 4th, 1917, in collapsed condition. Right forearm shattered ; compound fracture of right femur with severing of popliteal vessels. Anti-shock measures carried out, but only slight improvement resulted. Blood transfusion .(1,000 c.cm.) was followed by immediate and marked improvement. Amputation through forearm and thigh now done. The patient withstood operation well, but died in thirty-six hours from extensive gas gangrene of right thigh.

CASE 32.-G.S.W. Thigh and Lef : Evacuated in Good Condition.

Pte. D. O'L. Admitted August 5th, 1917, in very collapsed condition; had sustained, forty-elght hours previously, a large
wound in left thigh, and while lying out in a shell-hole twenty. wound in left thigh, and while lying out in a shell-hole twentythe hours later lad received a second and extensive wound in latter. Anti-shock measures were instituted, but with only slight improvement. Immediate improvement followed blood transfusion $(1,100 \mathrm{c.cm}$.). Before transfusion: pulse 132, blood pressure 90. After transfusion: pulse 96, blood pressure 142 One hour later operation was done. Further progress good. Evacuated to the base in two.days in very gool condition. It is interesting to note that at the end of the transfusion there was a marked urticarial eruption (serum rash?) over the trunk and extremities. It had subsided in less than twenty-four hours.

Case 33.-G.S.W. Knee: : Amputation: Evacuated to Base in Good Condition:

Lieut. J. K. P. Admitted August 5th, 1917 (under the care of Captain W. Beggs, C.A.M.C), in very poor condition, twentyfour hours after sustaining a severe compound fracture of the left log into knee-joint with damage to vessels. After antishock measures, drainage established and bleeding controlled. The next day the pulse was very rapid, face still blanched, leg becoming swollen. Blood transfusion (530 c.cm.). Before transfusion:- pulse 178. "After transfusion:- pulse, 132. Am putation above knee. Further progress uneventful. Evacuated to base on August 9th in good condition; pulse 90 .

CASE 34.-G.S.W. Thigh: Amputation: Death.

Pte. J. W. Admitted August 10th, 1917. Wounded twelve hours before. Extensive comminution of right femur; anterior muscles blown away; but hamstrings intact; femoral vessels torn. Condition of profound collapse. Anti-shock measures jnstituted on admission with very little effect. Blood transfusion $(1,000 \mathrm{c.cm}$.) two hours later. Before transfusion: pulse fusion (1,000 c.cm.) two hours later. Before transfusion: pulse
152, blood pressure 72 . After transfusion: pulse 130, blood pressure 146. Patient suffering from toxaemia due to gangrenous condition of muscles. High amputation done one hour after transfusion, but intramuscular planes found to be extensively infected up to groin. Death twenty hours later.
CASE 35.-G.S.W. Knee: Amputation : Evacuated in Good Condition.

Lce.-Cpl. L. H. Wounded the previous evening; admitfed on morning of August 11th, 1917. Right leg shattered, involving knee-joint; part of right tarsus blown away. Anti-shock measures for several hours, with no effect. Blood transfusion (700 c.cm.). Before transfusion: pulse 152 ; blood pressure systolic 60 , diastolic 0 . After transfusion: pulse 114 ; blood pressure: systolic 120 , diastolic 60 . Amputation above right pressure: systolic 120, diastolic 60. Amputation above right good condition on fourth day.

CaSe 36.-G.S.W. Popliteal Artery and Vein: Amputation: Evacuated in Good Condition.

Pte. A. H. C. Aãmitted August 11th, 1917, collapsed and almost pulseless; had bled profusely from gaping wound in right popliteal space. Anti-shock measures had very little effect. Blood transfusion (1,000 c.cm.) was followed by immediate improvement. Before transfusion: pulse 124 ; bloo pressure : systolic 74, diastolic 15. After transftision: pulse 110 blood pressure: systolic 142, diastolic 68. Amputation above wound two hours later under gas-oxygen anaesthesia. Examination of amputated leg showed complete division of popliteal vein and large tear in popliteal artery. Further progress uneventful. Evaçuated to base in good condition on fourth day.

In reviewing these cases of primary haemorihage I feel that better results might have been obtained in Cases 1 , 7, and 18. In Case 1 the fatal issue was due to the early development of gas gangrene, which might have been eliminated by amputation had the transfusion been done earlier. In Case 9 an earlier transfusion would have permitted earlier amputation, which would have rendered less likely the development of gas gangrene. Though the infection in this case was controlled it was responsible, apparently, for thrombosis in the femoral vein with subsequent death from pulmonary embolism. Case 18 was seen during the rush of the Messines battle. Measures to counteract shock were carried out in the resuscitation ward, but were unsuccessful. Although the blood transfusion produced a startling improvement his toxaemia was too intense to allow him to withstand the anaesthetic and the shock of the operation.

\section{Conclusions.}

1. Many cases admitted in an inoperable condition from severe haemorrhage liave been rendered operable by blood transfusion.

2. The largest factor in the causation of the condition of shock as seen in patients admitted to a casualty clearing station appears to be the loss of blood, except in cases of visceral injury.

3. In two cases haemolysis hastened the death of the patient. In one of these the citrate method was used. The possibility of haemolysis certainly is present, but the danger of its occurrence is slight in comparison with the danger of operating on a shocked and exsanguined patient.

4. The results in this series of cases of severe primary haemorrhage may be classified as:

$\begin{array}{cccccccc}\text { Life saving } & \ldots & \ldots & & & & \\ \text { Immediately beneficial, but died from } & \ldots & & \\ \text { infection } & \\ \text { or operation } & \ldots & : \ldots & \ldots & \ldots & \ldots & \ldots & 9 \\ \begin{array}{c}\text { No benefit } \\ \text { Harmful }\end{array} & \ldots & \ldots & \ldots & \ldots & \ldots & \ldots & 3 \\ \quad \text { Total } & \ldots & \ldots & \ldots & \ldots & \ldots & 36\end{array}$

5. Although the mortality in this series of cases is com, paratively high, it must be remembered that all the patients were in a desperate condition, and with, perhaps, one possible exception, could not have been expected to survive if the procedure had been withheld.

REFERENCES.

1 L. B. Robertson, British MEDICAL JoURNaL, July 8th, 1916: 2 Edward Lindeman, Amer. Journ. Dis. Child., July, 1913: 8 A: Fullerton, G. Dreyer, and H. C. Bazett, Lancet, May 12th, 1917.

Note by Colonel C. GORDON WATSON.

During the past year I have had the opportunity of observing the technique and the results of blood trans. fusion by Major Bruce Robertson and other workers.

Without doubt transfusion of blood after primary haemorrhage is a life-saving device of the greatest value and enables urgent operations to be successfully performed under conditions otherwise hopeless. In the past blood transfusion has failed to come to the fore owing to technical difficulties. The stimulus of war and the 
urgent need for blood transfusion has resulted in greater familiarity with the technique.

For many years past we have, in England at any rate, trusted to saline infusion to restore the balance after haemorrhage. So far as my experience goes, there is no comparison between the results of blood transfusion and saline infusion. The effects of blood transfusion are instantaneous and usially lasting; the effects of saline too often transitory-a flash in the pan-followed by greater collapse than before.

In civil practice, speaking generally, the occasions for transfusion are few; in military practice, in the forward line, the exsanguined wounded man is regularly met with in the reception room.

The problems of shock and collapse are recoiving every day greater attention. In every casualty clearing station there is a resuscitation ward with beds lieated by hot air or electric light and with arrangements for giring hypertonic intravenous infusions, and so on. Here wo endeavour to estimate the shock of battle, the shock that follows trauma or loss of blood, or the shock of toxaemia, to assess the proportionate damages to each, and to apply the appropriate remedy.

The methods of blood transfusion employed in tho casualty clearing stations vary with the indiviclual surgeon. Major Robertson has acquired great dexterity with the syringe method, and his results are correspondingly good.

Practice. in team work is essential to success, and the two surgeons and the syringe orderly must drill together. Record syringes can be relied on for the purpose; other's cannot.

The scope of blood transfusion is not limited to primary haemorrhago. It is of undoubted value for 'secondary haemorrhage, and we have nsed it successfully also as a sequel to venesection in two severe cases of carbon monoxide poisoning.

In the selection of a donor for blood transfusion, certain precautions should be taken when the circumstances of the case permit. At the front, particularly during the periods of heavy fighting, time does not permit of tests to eliminate syphilitic taint, nor, indeed, to ascertain if the blood of the donor is incompatible with that of the patient. Such risk as there is must be run if the urgent need of the patient is to be met promptly.

I have more than once seen alarming symptoms arise during transfusion. In one case the pupils dilated, the eyes were turnea up, the pulse-rate increased, and the patient became pallid and unconscious, and died the same day. At the necropsy the blood was completely haemo. lysed. The condition of the wounds, however, showed that the chances "of recovery were remote. In other instances $I$ have noted transitory respiratory distress, sweating aud preoordial pain, followed subsequently by a varying amount. of haemoglobinuria. The occurrence of rigors with a transitory rise of temperature are by no means uncommon after transfusion and are not an indica. tion of imcompatibility of bloods.

Too rapid transfusion may be follarved by acute dilatation of the lieart when the myocardium is exhausted and weakened by haemoirliage and shock. As Crile has pointed aut, the work of the heart increases in geometric ratio to the volume of blood, and it is easy to realize the risk involved in suddenty producing a rapid increase in the volume of blood when the heart is already tired out. I have seen this exemptified in one case.

I feel confident that blood transfusion has become a permanent method, and that under the stimulus of war and the mass of material that war provides, our methods will steadily improve. The excellent results which Major Robertson has secured will, I hope, stimulate other surgeons to increased activity in the practice of this life-saving device.

WHEN delegates of the profession of the Republic of Uruguay recently visited France they were received at the Paris Faculty of Medicine on October .14th by Professor Gaucher, president of the General Medical Association of France, who recalled the fact that on the initiative of Professor Enrique Pouey of Montevideo the doctors of Uruguay had sent to the French fund for the medical victins of the war a sum of $£ 1,360$, contributed by 210 cloctors in a country of not more thian one million inhabi tants. Professor Pouey himself had sent the whole of his salary.

\section{DIRECT TRANSFUSION OF BLOOD.}

BY

Liect.-Colonel ALFRED J. HULL, F.R.C.S., ROYAL ARMY MEDICAL CORPS.

Although the advantages of direct transfusion are so apparent, this treatment does not appear to be in such frequent use as it merits.

Apart from its obvious indication in cases of severe haemorrhage, it would appear to be a valuable treatment for severe sepsis and shock. The provision of licalthy blood to patients suffering from septicaemia must supply

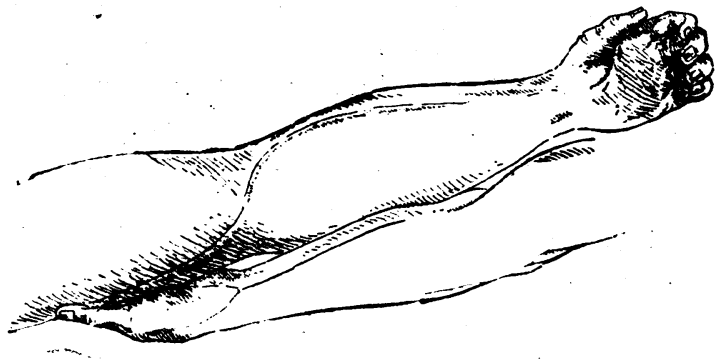

Fic. 1.-The position of the arms. The donor's left hand grasps the patient's left arm well above the elbow, bringing the donor' radial.artery almost into apposition with the patient's median

them with the bactericidal agents, bacteriolysins, antibodies, agglutinins, opsonins, leucocytes, and tryptic power which they are deficient in.

How far the alteration of the blood in cases of shock determines the result is at present uncertain, but the effect of healthy blood upon the tissues of such patients appears to be worthy of consideratiou.

Transfusion would appear to be a more scientific remedy than the empirical injection of antiseptics into the blood stream.

The difficulty of obtaining some one rvilling to submit to an operation entailing ligature of an artery is in my opinion the only bar to a much greater use of this treatment.

The operation is very simple and can be performed without the use of special apparatus. In fact, I consider the use of any apparatus most undesirable.

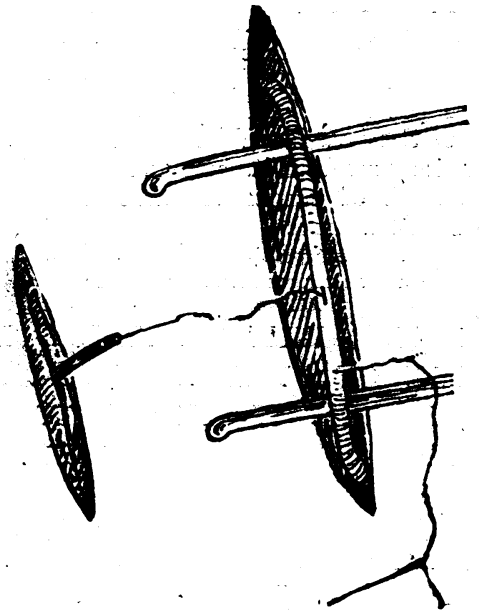

Fra. 2.-The preparation of the vesscls. The radial artery has been cleaned for about an inch, divided, and drawn out of th wound. A traction suture has been tied on to the artery. The patient s vein has been exposed and lifted by two probes. By he in

To be efficient and certain in its results the operation should be performed by the direct transfusion of blood from artery to vein. It is only in this way that clotting, the one danger of transfusion, can be aroided with certainty. 'The only disadvantage of this method is that the amount of blood transfused caunot be measured, but this is outweighed by the safety and simplicity of the method, and moreover the amount of blood which flows before the donor becomes faint is fairly constant. 